\title{
Coronally advanced flap with or without porcine collagen matrix for root coverage: a randomized clinical trial
}

\author{
Ana Regina Oliveira Moreira ${ }^{1} \cdot$ Mauro Pedrine Santamaria $^{2} \cdot$ Karina Gonzales Silvério $^{1} \cdot$ \\ Marcio Zaffalon Casati ${ }^{1}$ - Francisco Humberto Nociti Junior ${ }^{1}$ • Anton Sculean ${ }^{3}$. \\ Enilson Antonio Sallum ${ }^{1}$
}

Received: 29 May 2015 / Accepted: 16 February 2016 / Published online: 26 February 2016

(C) Springer-Verlag Berlin Heidelberg 2016

\begin{abstract}
Objectives The objective of this study is to clinically evaluate the outcomes following treatment of single gingival recessions with either coronally advanced flap technique (CAF) alone or combined with a porcine collagen matrix graft (CM). Materials and methods This is a randomized parallel design clinical trial, including forty patients with single Miller Class I or II gingival recession, with a depth $\geq 2 \mathrm{~mm}$ and located at upper canines or premolars. The patients were randomly assigned to receive either CAF or CAF + CM. The primary outcome variable was gingival recession reduction (Rec Red). Results Baseline recession depth was $3.14 \pm 0.51 \mathrm{~mm}$ for CAF group and $3.16 \pm 0.65 \mathrm{~mm}$ for CAF + CM group $(p>0.05)$. Both groups showed significant Rec Red $(p<0.05)$, up to 6 months. Rec Red for CAF + CM was $2.41 \pm 0.73 \mathrm{~mm}$ and was $2.25 \pm 0.50 \mathrm{~mm}$ for CAF alone $(p>0.05)$. Root coverage was $77.2 \%$ in the CAF + CM group and $72.1 \%$ in the CAF group $(p>0.05)$. Complete root coverage (CRC) was found in $40 \%$ of the cases in the $\mathrm{CAF}+\mathrm{CM}$ group and in $35 \%$ of the sites treated with CAF. Keratinized tissue thickness (KTT) was $0.26 \mathrm{~mm}$ higher in $\mathrm{CAF}+\mathrm{CM}$ group $(p<0.05)$.
\end{abstract}

Enilson Antonio Sallum enilson@unicamp.br

1 Department of Prosthodontics and Periodontics, Division of Periodontics, Piracicaba Dental School, State University of Campinas - UNICAMP, Av. Limeira, 901, Areião, Piracicaba, São Paulo, Brazil

2 Department of Periodontology, São José dos Campos Dental School, State University of São Paulo, São José dos Campos, São Paulo, Brazil

3 Department of Periodontology, University of Bern, Bern, Switzerland
Conclusions It can be concluded that CAF + CM does not provide a superior recession reduction when compared to CAF; however, it may offer a small gain in KTT after 6 months.

Clinical relevance $\mathrm{CAF}+\mathrm{CM}$ can be suggested as a valid therapeutic option to achieve root coverage and some increase in soft tissue thickness after 6 months.

Keywords Gingival recession/surgery · Collagen/therapeutic use $\cdot$ Root coverage $\cdot$ Treatment outcome

\section{Introduction}

Gingival recession is characterized by the apical displacement of the gingival margin in relation to the cementoenamel junction (CEJ), which results in the exposure of the root surface to the oral environment [1]. Its occurrence is frequent both in patients with poor and high standard oral hygiene [2-6]. Plaque-induced inflammation and toothbrush trauma have been proposed as etiologic factors [6-8], even though this point still needs elucidation [9].

Gingival recession is frequently associated with esthetic complaints, presence of caries and non-carious cervical lesions [10, 11] and dentin hypersensitivity [10, 12-14]. Therefore, many periodontal plastic surgery techniques have been widely used for treatment of gingival recession with high predictability in clinical practice [11] such as coronally advanced flap (CAF) [10], with or without subepithelial connective tissue graft (SCTG) [15], allograft acellular dermal matrix graft (ADM) [16], and regenerative materials [17, 18].

CAF alone presents favorable clinical outcomes despite the large variability of findings in the literature [19]. Additionally, CAF in combination with SCTG may increase the possibility of complete coverage of the exposed root [11, 14, 19-22]. 
However, longer surgical time, [23] pain, and postoperative complications are frequently reported by patients treated with SCTG [23-26].

In order to avoid the morbidity associated with the harvesting of autogenous grafts, ADM have been used as a substitute for palatal donor tissue $[16,27,28]$. When compared with a control group treated by CAF alone, no significant difference was observed after 6 months in recession reduction, but ADM provided greater keratinized tissue thickness [16]. After a longer follow-up period (2 years), the ADM treated group showed a reduced residual recession when compared with $\mathrm{CAF}$ alone [27]. However, $\mathrm{CAF}+\mathrm{ADM}$ or CAF + GTR were considered to be less effective than CAF + SCTG in terms of root coverage results [19].

The use of a collagen matrix (CM) of porcine origin is an alternative that has recently emerged [29-33]. The structure of this new matrix consists of a cell occlusive layer, with compact collagen fibers, and a spongious layer with porous collagen structure. The thickness of this porous layer is supposed to provide blood clot stabilization and space which could promote cell migration and might result in increased formation of keratinized tissue [34, 35].

Based on this assumption, it is suggested that the association of this collagen matrix with CAF can be a valid alternative to increase the predictability of the treatment of gingival recession defects [19]. However, until now, only one randomized clinical trial (RCT) has evaluated the additional use of CM compared to CAF alone [32]. The aim of the present study was to evaluate if the combination of CAF with a porcine collagen matrix (CM) graft could provide superior clinical outcome in the treatment of localized Miller Class I and II gingival recessions.

\section{Materials and methods}

\section{Experimental design}

The study was designed as a parallel-group, single-blinded, randomized controlled clinical trial (Fig. 1). Forty patients showing gingival recessions were randomly assigned to receive one of the following treatments:

1. CAF group $(n=20)$ : The recession was treated by the CAF procedure alone.

2. $\mathrm{CAF}+\mathrm{CM}$ group $(n=20)$ : The recession was treated by CAF combined with $\mathrm{CM}$ as a subepithelial graft (Mucograft®; Geistlich Pharma AG, Wolhusen, Switzerland).

\section{Sample size}

Sample size calculation for this superiority trial was performed considering gingival recession reduction (Rec Red) as the primary outcome. The study was powered to detect a minimum clinically significant difference in root coverage of $1.0 \mathrm{~mm}$ by assumption of $\alpha=0.05$, power $=95 \%, \sigma=0.67$, based on data from a previous study [16]. Thirteen patients per treatment arm were needed in the present trial. Considering dropouts, a total sample of 20 subjects per group was enrolled

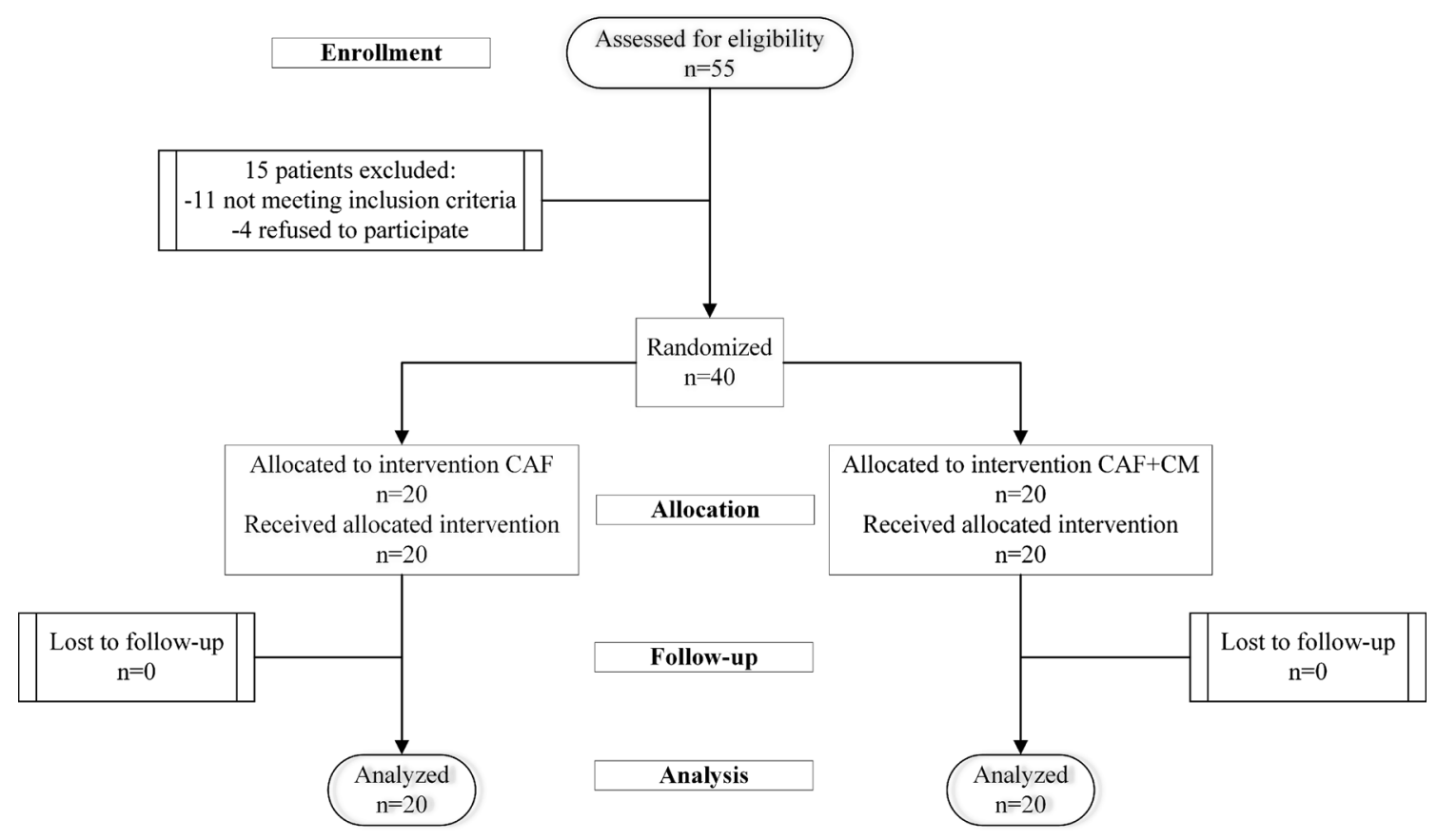

Fig. 1 Consort flowchart of the study 
to achieve the power of the study. No subjects were lost up to the follow-up at 6 months.

\section{Study population}

The study protocol has been approved by the Institutional Review Board of the Piracicaba Dental School, State University of Campinas (CEP-UNICAMP 130/2010). Informed consent was obtained of each subject after a thorough explanation of the nature, benefits, and possible risks of the clinical investigation procedures. The informed consent was in accordance with the Helsinki Declaration of 1975 as revised in 2008. The study was registered at ClinicalTrials.gov as NCT02242500.

A total of 40 eligible subjects were enrolled in the study from a group of patients referred for periodontal treatment to the Graduate Clinic of the Piracicaba Dental School, State University of Campinas (FOP-UNICAMP), according to the following inclusion criteria:

- Age $\geq 18$ years

- Presence of at least one Class I or II Miller gingival recession $\geq 2 \mathrm{~mm}$ in maxillary canines or premolars with identifiable CEJ and without deep non-carious cervical lesions $(<0.5 \mathrm{~mm}): \mathrm{A}+[36]$

- Esthetic complaint and/or presence of dentin hypersensitivity to air stimulus

- Full-mouth visible plaque index $\leq 20 \%$ [37]

- Full-mouth sulcus bleeding index $\leq 20 \%$ [38]

Exclusion criteria were the following:

- Smoking

- Pregnancy

- Presence of systemic disorders (diabetes, hypertension, heart disease, or any other condition that could contraindicate periodontal surgery)

- Use of medications (immunosuppressants, phenytoin, or anything else that might affect mucosal healing and repair)

- Previous periodontal surgery in the area

\section{Randomization, allocation concealment, and blinding}

The randomization of the patients was performed by computer-generated randomization table prepared by an investigator with no clinical involvement in the trial. Allocation concealment was obtained using a sealed coded opaque envelope containing the treatment to the specific subject. After local anesthesia and flap elevation, the envelope corresponding to the patient was opened and the assigned treatment was performed. The examiner remained blinded to the treatment assignment.

\section{Clinical assessments}

All clinical measurements were performed by a blinded examiner (A.R.O.M.), who was calibrated to obtain acceptable intra-examiner reproducibility for the parameters: relative gingival recession (gingival margin to stent), probing depth, and recession depth (gingival margin to the CEJ). The obtained intra-class correlation coefficient was 0.89 for relative gingival recession, 0.92 for probing depth, and 0.94 for recession depth measurements. The auto-curing acrylic resin stent (Duralay, Reliance, Illinois, USA) was fabricated over a stone cast that was prepared after maxillary impression. The stents were trimmed at the coronal third of the tooth in order to leave inter-dental papillae visible and ensuring a flat and linear edge. A groove was made on the stent at the mid-buccal area of the experimental tooth to allow a reproducible periodontal probe positioning. The apical margin of the stent was used as reference point for relative clinical measurements. The following clinical parameters were assessed at baseline, 45 days, 2, 3, and 6 months after surgical procedures:

- Full-mouth visible plaque index (FMPI) [37] and presence or absence of visible plaque at the site included in the study.

- Full-mouth sulcus bleeding index (FMBI) [38] and presence or absence of bleeding on probing (BOP) at the site included in the study.

- Relative gingival recession (RGR), measured as the distance from the GM to the reference point of the stent. This parameter was used to calculate the reduction of gingival recession (Rec Red) as the difference between RGR at baseline and RGR at each time point.

- Probing depth (PD) assessed as the distance from the GM to the apical end of the gingival sulcus.

- Gingival recession (GR), measured as the distance from the GM to the CEJ. In cases where the gingival margin covered the CEJ, this parameter was considered as equal to 0 .

- Clinical attachment level (CAL) calculated as PD + GR.

- Keratinized tissue width (KTW), measured from the GM to the mucogingival junction (MGJ), evidenced with Lugol staining.

- Keratinized tissue thickness (KTT) measured at a midpoint between GM and MGJ (da Silva et al. 2004; Santamaria et al. 2008).

PD and KTW were measured using a University of North Carolina periodontal probe (Hu-Friedy, Chicago, IL, USA). Measurements of GR and RGR were performed using a pair of dividers and a digital caliper accurate to $0.01 \mathrm{~mm}$. KTT was measured using an 
endodontic spreader pierced perpendicular and through the soft tissue with light pressure until a hard surface was felt. The silicone stop was then placed in tight contact with the external soft tissue surface. After carefully removing the spreader, penetration depth was measured with a digital caliper. Dehiscence depth (DD) was measured during surgical procedures as the distance from the CEJ to bone crest.

The primary outcome of this trial was gingival recession reduction (Rec Red) at 6 months.

\section{Dentin hypersensitivity assessment}

Dentin hypersensitivity (DHS) was measured at baseline and 6 months after surgery using the air spray. Therefore, the air blast from a triple syringe was applied to the exposed buccal cervical area for $1 \mathrm{~s}$ from a distance of approximately $1 \mathrm{~cm}$. The intensity of DHS was recorded by the patient on a visual analog scale (VAS) of $100 \mathrm{~mm}$.

\section{Patient centered esthetic evaluation}

Esthetic outcome was evaluated from the patient's point of view at baseline and 6 months after surgery using a VAS of $100 \mathrm{~mm}$.

\section{Pre-treatment}

All patients received oral hygiene instructions to correct any traumatic tooth brushing habit that could be related to the etiology of the recession, at least 4 weeks before surgery. A pre-surgical supragingival scaling procedure with ultrasound device (Cavitron Select-Dentsply International Inc., Long Island City, NY, USA) and dental prophylaxis/polishing was performed 2 weeks before the scheduled surgical procedure.

\section{Surgical procedures}

All surgical procedures were performed by the same trained and skilled periodontist (M.P.S.). The control group was treated with $\mathrm{CAF}$, while the test group received $\mathrm{CAF}+\mathrm{CM}$.
Fig. 2 Recession defect test site. a Pre-operative image of an upper left canine presenting Miller Class I recession. b Flap design. c Exposed root surface after the elevation of the flap. $\mathbf{d}$ The collagen matrix has been sutured to cover the exposed root surface. e The pedicle flap has been coronally positioned and sutured to cover the graft and the cementoenamel junction (CEJ). $\mathbf{f}$ At 6 months, the exposed root surface is completely covered
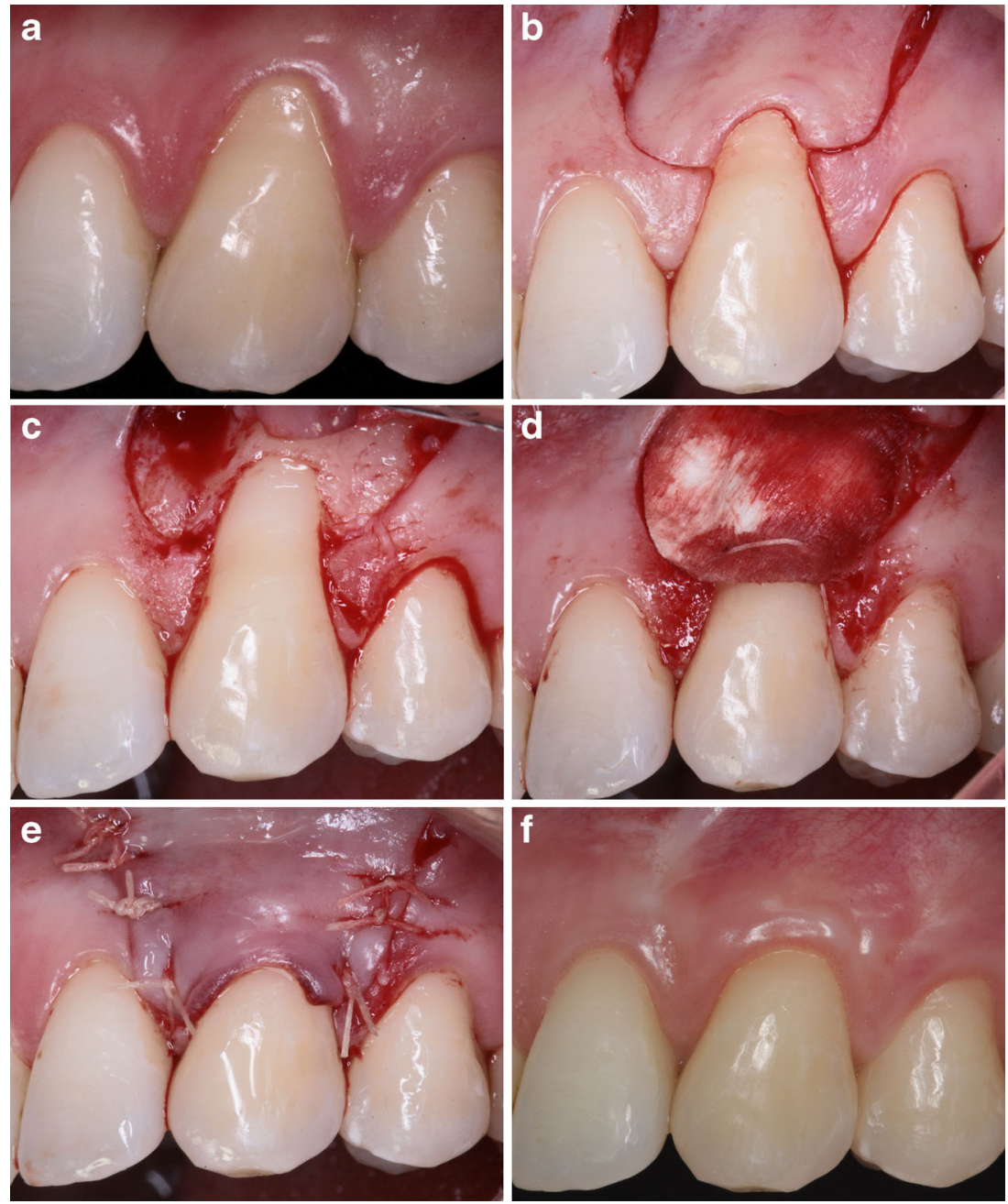
After local anesthesia (Lidocaine with 1:100,000 epinephrine, DFL, Rio de Janeiro, RJ, Brazil), intrasulcular incision was made at the buccal site of the involved tooth, followed by two horizontal incisions performed at the adjacent papillae, at the level of the CEJ, without interfering with the gingival margin of the adjacent tooth. These horizontal incisions were continued by two oblique incisions extended beyond the MGJ, and a trapezoidal mucoperiosteal flap was raised up to the MGJ. Afterwards, a partial thickness flap was extended apically to the MGJ in order to release tension and favor the coronal positioning of the flap. The adjacent papillae were deepithelized, and the debridement of the root surface was performed by manual instrumentation with Gracey curettes (Hu-Friedy, RJ, Brazil). At sites designated to receive treatment with $\mathrm{CAF}+\mathrm{CM}$, the $\mathrm{CM}$ was used according to the manufacturer's instructions (Geistlich Pharma AG, Wolhusen, Switzerland). The matrix was cut to achieve proper shape and size to cover the entire root surface and surrounding bone. The matrix was positioned at the level of CEJ, without prior hydration with saline solution, with the porous surface in contact with the bone and the tooth, while the smooth surface was facing the flap. The matrix was sutured with sling sutures (Vicryl®, Johnson \& Johnson, Skillman, NJ, USA). Subsequently, the flap was positioned coronally and sutured with sling sutures so as to completely cover the matrix. The releasing incisions were sutured with simple interrupted sutures (Fig. 2). Caution was taken to avoid overcompression of the matrix. In the sites treated with CAF alone, surgical procedures were identical except for the application of the graft. All sites presented the CEJ completely covered at the end of the surgical procedure (Fig. 3).

Anti-inflammatory corticosteroid medication was administered $1 \mathrm{~h}$ before surgery and $12 \mathrm{~h}$ later $(4 \mathrm{mg}$ Dexamethasone, Ache Pharmaceutical Laboratories SA, Guarulhos, SP). For pain control, postoperative analgesics were prescribed four times a day for 3 days $(500 \mathrm{mg}$ Dipyrone, Ache Pharmaceutical Laboratories SA, Guarulhos, SP). In addition, patients were instructed to rinse twice daily with chlorhexidine $(0.12 \%)$ for $1 \mathrm{~min}$ and to avoid mechanical trauma and discontinue tooth brushing in the surgical site for 14 days.

Sutures were removed after 14 days and patients were instructed to resume an atraumatic tooth brushing technique
Fig. 3 Recession defect control site. a Pre-operative image of an upper left canine presenting Miller Class I recession. b Flap design. c Exposed root surface after the elevation of the flap. $\mathbf{d}$ A pedicle flap has been sutured coronal to the CEJ. e Complete root coverage was achieved at 6-month examination
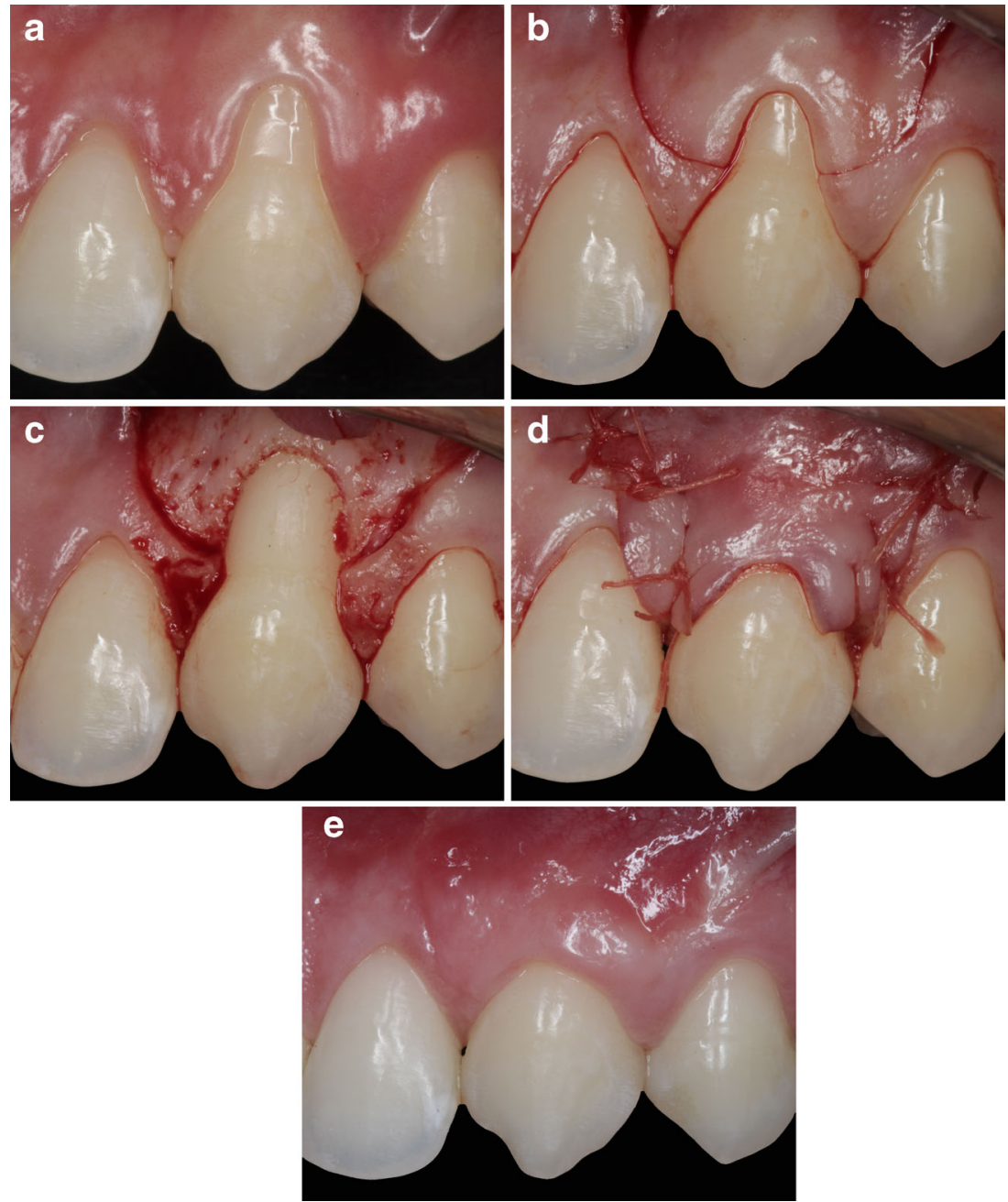
with soft-bristle toothbrush and inter-dental cleaning. All patients were enrolled in a periodontal maintenance program (professional plaque control and oral hygiene instruction) weekly during the first month and monthly during the 6 months.

\section{Statistical analysis}

The analysis was performed to test the hypothesis that CAF combined with CM would result in improved outcomes (superiority trial). Descriptive statistics were expressed as mean \pm standard deviation (SD). For intergroup analysis at baseline, Student's $t$ test for two independent samples and $X^{2}$ test was used. For clinical parameters CAL, Rec Red, and RC, comparisons were performed by repeated measures of analysis of variance (ANOVA) and Tukey's test. FMPI, FMBI, PD, GR, RGR, KTT, KTW, and KTT increase were analyzed by Friedman's test. The intergroup analysis was performed by Mann-Whitney test. Visible plaque and BOP at the site included in the study were examined by Fisher's exact test. All tests were performed using the software SAS 9.2 (The SAS Institute, Cary, NC, USA) at a significance level of $5 \%$.

\section{Results}

The study included 40 patients (mean age: $34.4,25$ women, 15 men), recruited and treated between 2010 (December) and 2013 (April). All patients were able to complete the follow-up examination after 6 months. Baseline patient- and defect- related characteristics showed no statistically significant differences between groups $(p>0.05)$ (Table 1).

The FMPI and FMBI remained between 8 and $22 \%$ during the entire study period. At baseline, all sites included in the study showed no presence of visible plaque or BOP. However, at 45 days follow-up, the presence of plaque and BOP were observed at five sites in the CAF group ( $25 \%$ ) and four sites in the $\mathrm{CAF}+\mathrm{CM}$ group $(20 \%)$, with no statistically significant difference between groups $(p>0.05)$. At 2,3 , and 6 months follow-up periods, none of the sites showed the presence of visible plaque or BOP. No complications were observed during the surgical procedure. Furthermore, there were no adverse reactions during the entire study period.

The clinical parameters recorded at the different periods are shown in Table 2. When considering PD and CAL, no statistically significant differences could be observed between groups in any of the evaluated periods. However, when considering within the groups comparisons, PD values did not show significant differences among periods $(p>0.05)$ while a significant change was observed for CAL related to the baseline value $(p<0.05)$. Regarding RGR, a statistically significant reduction was observed for both groups $(p<0.05)$. This parameter changed from $6.05 \pm 0.53 \mathrm{~mm}$ to $3.80 \pm 0.67 \mathrm{~mm}$ at 6 months in CAF group and from $6.48 \pm 0.89$ to $4.06 \pm 0.83$ in CAF $+\mathrm{CM}$ group. The comparison between groups showed no statistically significant difference $(p<0.05)$ (Table 2). Both groups showed significant Rec Red after 6 months $(p<0.05)$. Rec Red for patients treated with $\mathrm{CAF}+\mathrm{CM}$ was $2.41 \pm 0.73 \mathrm{~mm}$ and $2.25 \pm 0.50 \mathrm{~mm}$ for patients treated with CAF alone, with no statistically significant difference between groups $(p>0.05)$ (Table 3$)$. Therefore, the mean recession depth decreased from 3.14 to
Table 1 Baseline patient and defect-related characteristics

\begin{tabular}{llll}
\hline & CAF $(n=20)$ & CAF + CM $(n=20)$ & $p$ value \\
\hline Age [mean \pm SD (years), range] & $34.7 \pm 9.63(23-59)$ & $34.05 \pm 7.56(22-49)$ & 0.81 \\
Gender (female/male) & $14 / 6$ & $11 / 9$ & 0.33 \\
Type of tooth (canine/pre-molar) & $11 / 9$ & $13 / 7$ & 0.20 \\
FMPI [mean \pm SD (\%)] & $17.26 \pm 2.54$ & $17.41 \pm 1.77$ & 0.68 \\
FMBI [mean \pm SD (\%)] & $17.35 \pm 2.05$ & $17.65 \pm 1.60$ & 0.90 \\
PD [mean \pm SD (mm)] & $1.15 \pm 0,37$ & $1.14 \pm 0,35$ & 0.64 \\
GR [mean \pm SD (mm)] & $3.14 \pm 0,51$ & $3.16 \pm 0,65$ & 0.91 \\
CAL [mean \pm SD (mm)] & $4.24 \pm 0.64$ & $4.31 \pm 0.76$ & 0.75 \\
KTW [mean \pm SD (mm)] & $2.60 \pm 0,94$ & $2.60 \pm 0,88$ & 1.00 \\
KTT [mean \pm SD (mm)] & $1.01 \pm 0,18$ & $0.99 \pm 0,22$ & 0.75 \\
DD [mean \pm SD (mm)] & $5.65 \pm 0.88$ & $5.80 \pm 0.77$ & 0.57 \\
\hline
\end{tabular}

$p$ values testing differences between treatment groups were calculated using Student's $t$ test

$C A F$ coronally advanced flap, $C M$ porcine collagen matrix, $S D$ standard deviation, FMPI full-mouth plaque index, $F M B I$ full-mouth bleeding index, $P D$ probing depth, $G R$ gingival recession depth, $C A L$ clinical attachment level, $K T W$ keratinized tissue width, $K T T$ keratinized tissue thickness, $D D$ dehiscence depth (intra-surgical measurement) 
Table 2 Clinical parameters recorded at baseline, 45 days, 2,3 , and 6 months after surgery in $\mathrm{mm}$ $($ mean $\pm \mathrm{SD})$

\begin{tabular}{|c|c|c|c|c|c|}
\hline & Baseline & 45 days & 2 months & 3 months & 6 months \\
\hline \multicolumn{6}{|l|}{ PD } \\
\hline $\mathrm{CAF}$ & $1.10 \pm 0.31^{\mathrm{a}}$ & $1.35 \pm 0.59^{\mathrm{a}}$ & $1.25 \pm 0.44^{\mathrm{a}}$ & $1.15 \pm 0.37^{\mathrm{a}}$ & $1.20 \pm 0.41^{\mathrm{a}}$ \\
\hline $\mathrm{CAF}+\mathrm{CM}$ & $1.15 \pm 0.37^{\mathrm{a}}$ & $1.65 \pm 0.75^{\mathrm{a}}$ & $1.50 \pm 0.76^{\mathrm{a}}$ & $1.40 \pm 0.50^{\mathrm{a}}$ & $1.10 \pm 0.31^{\mathrm{a}}$ \\
\hline \multicolumn{6}{|l|}{ GR } \\
\hline CAF & $3.14 \pm 0.51^{\mathrm{a}}$ & $0.72 \pm 0.53^{b}$ & $0.76 \pm 0.53^{b}$ & $0.80 \pm 0.54^{b}$ & $0.89 \pm 0.52^{b}$ \\
\hline $\mathrm{CAF}+\mathrm{CM}$ & $3.16 \pm 0.65^{a}$ & $0.48 \pm 0.80^{\mathrm{b}}$ & $0.65 \pm 0.69^{b c}$ & $0.66 \pm 0.74^{b c}$ & $0.75 \pm 0.76^{\mathrm{c}}$ \\
\hline \multicolumn{6}{|l|}{ RGR } \\
\hline CAF & $6.05 \pm 0.53^{\mathrm{a}}$ & $3.63 \pm 0.72^{b}$ & $3.67 \pm 0.70^{b}$ & $3.71 \pm 0.71^{\mathrm{b}}$ & $3.80 \pm 0.67^{b}$ \\
\hline $\mathrm{CAF}+\mathrm{CM}$ & $6.48 \pm 0.89^{\mathrm{a}}$ & $3.78 \pm 0.90^{\mathrm{b}}$ & $3.97 \pm 0.76^{b c}$ & $3.94 \pm 0.79^{b c}$ & $4.06 \pm 0.83^{c}$ \\
\hline \multicolumn{6}{|l|}{ CAL } \\
\hline CAF & $4.24 \pm 0.64^{\mathrm{a}}$ & $2.07 \pm 0.68^{b}$ & $2.01 \pm 0.60^{b}$ & $1.95 \pm 0.65^{b}$ & $2.09 \pm 0.70^{b}$ \\
\hline $\mathrm{CAF}+\mathrm{CM}$ & $4.31 \pm 0.76^{\mathrm{a}}$ & $2.13 \pm 0.87^{b}$ & $2.16 \pm 0.89^{b}$ & $2.05 \pm 0.75^{b}$ & $1.85 \pm 0.73^{b}$ \\
\hline \multicolumn{6}{|l|}{ KTT } \\
\hline $\mathrm{CAF}$ & $1.02 \pm 0.10^{\mathrm{a}}$ & $1.30 \pm 0.28 * \mathrm{~b}$ & $1.22 \pm 0.30 * \mathrm{ab}$ & $1.19 \pm 0.29 * \mathrm{ab}$ & $1.16 \pm 0.31 * a b$ \\
\hline $\mathrm{CAF}+\mathrm{CM}$ & $0.99 \pm 0.14^{\mathrm{a}}$ & $1.58 \pm 0.47 * \mathrm{~b}$ & $1.49 \pm 0.19 * \mathrm{~b}$ & $1.41 \pm 0.21 * \mathrm{~b}$ & $1.39 \pm 0.18 * \mathrm{~b}$ \\
\hline \multicolumn{6}{|l|}{ KTW } \\
\hline CAF & $2.60 \pm 0.94^{\mathrm{a}}$ & $2.70 \pm 0.98^{\mathrm{a}}$ & $2.65 \pm 1.04^{\mathrm{a}}$ & $2.70 \pm 0.92^{\mathrm{a}}$ & $2.75 \pm 0.97^{\mathrm{a}}$ \\
\hline $\mathrm{CAF}+\mathrm{CM}$ & $2.60 \pm 0.88^{\mathrm{a}}$ & $2.55 \pm 1.00^{\mathrm{a}}$ & $2.70 \pm 0.92^{\mathrm{a}}$ & $2.75 \pm 0.85^{\mathrm{a}}$ & $2.80 \pm 0.83^{\mathrm{a}}$ \\
\hline
\end{tabular}

Different letters indicate significant differences within groups over time by ANOVA/Tukey's tests (CAL) and Friedman test (PD, GR, KTT, and KTW) $(p<0.05)$. Asterisk indicates differences between groups at each time point by Mann-Whitney test $(p<0.05)$

$C A F$ coronally advanced flap, $C M$ porcine collagen matrix, GR gingival recession depth, KTT keratinized tissue thickness, $K T W$ keratinized tissue width, $S D$ standard deviation
$0.89 \mathrm{~mm}$ after 6 months for CAF treatment $(p<0.05)$. For cases treated with CAF + CM, the GR decreased from 3.16 to $0.75 \mathrm{~mm}$ at 6 months $(p<0.05)$. The percentage of RC was $72.1 \pm 14.4 \%$ with CAF and $77.2 \pm 21.2 \%$ in cases treated with $\mathrm{CAF}+\mathrm{CM}$, with no statistically significant difference between treatments $(p>0.05)$ (Table 3$)$. CRC was observed in $40 \%(n=8)$ of sites treated with CAF + CM compared to $35 \%(n=7)$ of sites treated with CAF alone $(p>0.05)$.
In cases treated with $\mathrm{CAF}+\mathrm{CM}$, KTT showed a statistically significant increase in all periods of follow-up compared to baseline $(p<0.05)$. In cases treated with CAF alone, a significant increase in KTT compared to baseline was observed only at 45 days follow-up. The comparison of KTT between the groups showed a statistically significant difference favoring $\mathrm{CAF}+\mathrm{CM}$ in all postoperative periods of follow-up (Table 2). When the differences between baseline
Table 3 Descriptive statistics of changes in the variables recorded at 45 days, 2, 3, and 6 months after surgery in $\mathrm{mm}($ mean $\pm \mathrm{SD})$

\begin{tabular}{|c|c|c|c|c|}
\hline & 45 days & 2 months & 3 months & 6 months \\
\hline \multicolumn{5}{|l|}{ Rec Red } \\
\hline CAF & $2.42 \pm 0.61^{\mathrm{a}}$ & $2.38 \pm 0.60^{\mathrm{ab}}$ & $2.34 \pm 0.52^{\mathrm{ab}}$ & $2.25 \pm 0.50^{b}$ \\
\hline $\mathrm{CAF}+\mathrm{CM}$ & $2.68 \pm 0.82^{\mathrm{a}}$ & $2.50 \pm 0.71^{\mathrm{ab}}$ & $2.51 \pm 0.75^{\mathrm{ab}}$ & $2.41 \pm 0.73^{b}$ \\
\hline \multicolumn{5}{|c|}{ Root coverage $(\%)$} \\
\hline CAF & $77 \pm 0.14^{\mathrm{a}}$ & $76 \pm 0.14^{\mathrm{ab}}$ & $75 \pm 0.15^{a b}$ & $72 \pm 0.14^{b}$ \\
\hline $\mathrm{CAF}+\mathrm{CM}$ & $86 \pm 0.24^{\mathrm{a}}$ & $80 \pm 0.20^{\mathrm{ab}}$ & $80 \pm 0.21^{\mathrm{ab}}$ & $77 \pm 0.21^{b}$ \\
\hline \multicolumn{5}{|l|}{ KTT increase } \\
\hline $\mathrm{CAF}$ & $0.27 \pm 0.25 * \mathrm{a}$ & $0.20 \pm 0.26^{* a}$ & $0.16 \pm 0.27 *^{\mathrm{a}}$ & $0.14 \pm 0.29^{*}$ \\
\hline $\mathrm{CAF}+\mathrm{CM}$ & $0.58 \pm 0.47 * \mathrm{a}$ & $0.50 \pm 0.19^{* a b}$ & $0.42 \pm 0.23^{* a b}$ & $0.40 \pm 0.19^{*} \mathrm{~b}$ \\
\hline
\end{tabular}

Different letters indicate significant differences within groups over time by Friedman test (KTT increase) and by ANOVA/Tukey's test (Rec Red and \% Root Coverage) $(p<0.05)$. Asterisk indicates differences between groups at each time point by Mann-Whitney test $(p<0.05)$

$C A F$ coronally advanced flap, $C M$ porcine collagen matrix, $\operatorname{Rec} R e d$ gingival recession reduction, $K T T$ keratinized tissue thickness, $K T W$ keratinized tissue width, $S D$ standard deviation 
and 6 months follow-up are considered, $\mathrm{CAF}+\mathrm{CM}$ resulted in an increased of KTT of $0.40 \mathrm{~mm}$ (from 0.99 to $1.39 \mathrm{~mm}$ ) compared to $0.14 \mathrm{~mm}$ in CAF group (from 1.02 to $1.16 \mathrm{~mm}$ ) $(p<0.05)$ (Table 3). Conversely, there was no within- and between-group increase in KTW $(p>0.05)$ (Table 2).

At 6 months, both treatment groups showed statistically significant DHS reduction when compared to baseline scores $(p<0.05)$. DHS scores reduced from $52.0 \pm 31.05$ to $19.5 \pm 20.38$ in patients treated with CAF and from $52.5 \pm 33.85$ to $10.5 \pm 15.72$ in patients treated with CAF + CM. This represents a DHS reduction of $62.5 \%$ for CAF group compared to $80 \%$ DHS reduction for $\mathrm{CAF}+\mathrm{CM}$ group. However, the inter-group analysis revealed no significant differences after 6 months $(p>0.05)$.

The results of patient esthetic satisfaction using VAS demonstrated a statistically significant improvement in esthetics satisfaction for both groups after 6 months (from $25.0 \pm 26.46$ to $93.5 \pm 7.45$ for CAF group and from $25.0 \pm 17.62$ to $94.0 \pm 10.46$ for $\mathrm{CAF}+\mathrm{CM}$ group) $(p<0.05)$. However, no significant difference was observed between groups after 6 months $(p>0.05)$.

\section{Discussion}

According to the available literature, better clinical outcomes may be expected when CAF procedure is associated with SCTG in the treatment of gingival recession, with further reduction of the recession defect and higher percentage of sites showing CRC $[19,22]$. It would be interesting to evaluate other less invasive options to improve the results of CAF. Thus, we hypothesized that a collagen matrix of porcine origin (CM) can also provide the chance for superior clinical outcomes. The present clinical trial has been designed to test the hypothesis of an additional clinical benefit with the placement of $\mathrm{CM}$ under a CAF procedure for the treatment of single Miller Class I and II gingival recessions, when compared to CAF alone.

The primary outcome of this study was gingival recession reduction (Rec Red) at 6 months. Both treatment groups resulted in significant Rec Red at 6 months $(\mathrm{CAF}=2.25 \mathrm{~mm}$ and $\mathrm{CAF}+\mathrm{CM}=2.41 \mathrm{~mm}$ ) but with no significant differences between the treatments. These values represented 72.5 and $77.8 \%$ of RC for CAF and CAF + CM group, respectively. The present clinical findings are in agreement to those reported by Jepsen et al. [32], who observed a mean recession reduction of $2.32 \mathrm{~mm}$ and $72.66 \%$ of RC for CAF group and $2.59 \mathrm{~mm}$ and $75.29 \%$ for CAF + CM group, with no difference between groups. However, they were lower than those presented by Mcguire and Scheyer [29] and Cardaropoli et al. [30]. The percentage of sites showing complete root coverage (CRC) reported by Cardaropoli et al. (2012) was $72 \%$ $(\mathrm{CAF}+\mathrm{CM})$. On the other hand, the figures reported by
Jepsen et al. (2013) for CRC (CAF $=31 \%$ and for CAF + $\mathrm{CM}=36 \%$ ) are in accordance with the results of the present study $(\mathrm{CAF}=35 \%$ and $\mathrm{CAF}+\mathrm{CM}=40 \%)$.

It is important to note that complete root coverage is a realistic goal in the treatment of Miller Class I and II gingival recessions and has been considered as an ideal outcome after root coverage procedures [19]. However, complete root coverage may not be the only factor contributing for final esthetic result since other factors can also influence esthetic perception such as soft tissue color and texture $[39,40]$. It is also interesting to note that significant improvement in the esthetic satisfaction of the patient was observed for both groups in the present study, although several sites did not show complete root coverage. Likewise, a significant reduction of dentin hypersensitivity was observed for both groups. Considering these aspects, Rec Red was used as the primary outcome variable of the present trial, showing the coronal change in the position of the gingival margin in $\mathrm{mm}$ and including the possibility of measuring this change in individual sites with the gingival margin coronally positioned in relation to the cementoenamel junction [41].

It is reasonable to consider that the small sample size is a limitation of this trial. The superiority of the combination of CM with CAF could not be demonstrated within the study period since it was powered to detect a minimum clinically significant difference in root coverage of $1.0 \mathrm{~mm}$. Thus, taken into account the great variability of the sample that reduces the ability to detect differences between groups, further studies with larger sample size and powered to detect a smaller difference in gingival recession reduction should be conducted to explore this possibility. In addition, disagreements among the results of different clinical trials emphasize the need for more clinical studies with different populations to further investigate the role of the association of this matrix to the CAF procedure.

Increased KTT was observed in CAF + CM group 45 days after the surgical procedures, which remained stable after 6 months. It is interesting to note that $\mathrm{CAF}+\mathrm{CM}$ group showed a mean gain in tissue thickness of $0.4 \mathrm{~mm}$, which was $0.26 \mathrm{~mm}$ larger than the CAF group. Jepsen et al. [32], with a similar short-term follow-up, observed an increase of 0.59 and $0.34 \mathrm{~mm}$ of KTT for CAF + CM and CAF, respectively, with an advantage of $0.25 \mathrm{~mm}$ for the cases treated with the CM. These findings are in agreement with the observations of the present study, despite the small difference in location for measuring the tissue thickness between studies. This parameter was measured at the mid-buccal point between the gingival margin and the MGJ in the present study, while in the Jepsen et al. [32] study, it was measured at a point $1 \mathrm{~mm}$ apical to the gingival margin. It may be considered that when using CAF + SCTG, da Silva et al. [42] showed that KTT increased $0.44 \mathrm{~mm}$ after 6 months. After a longer period (12 months), an increase of $0.6 \mathrm{~mm}$ was reported by Zucchelli et al. [43]. 
Ahmedbeyli et al. [44] showed that increasing KTT may be an important outcome in root coverage procedures. The authors presented significant positive correlation between KTT at 12 months and mean defect coverage after treatment with $\mathrm{CAF}$ associated or not to ADM. It also has been considered that a thin gingival biotype may be a factor that significantly increases the risk for the development of gingival recession [45]. Thus, the increase in KTT may be an important goal when trying to achieve superior long-term stability of soft-tissue margin [16]. It has been previously reported that a gain of $0.5 \mathrm{~mm}$ in KTT with the association of ADM with CAF could result in increased stability of gingival margin over time. The authors observed a smaller loss of root coverage between 6 and 24 months follow-up with the use of ADM (8\%) when compared with CAF alone (15\%) [27]. However, it is prudent to question if the small difference in the KTT observed between groups in the present study, is spite of being statistically significant, would be stable and able to provide a clinically meaningful benefit on a long-term basis.

The two treatments evaluated in the present study could not significantly change the KTW. Conversely, gains in KTW have been previously reported when CM was used in combination with CAF procedure [29, 30, 32]. Jepsen et al. [32] showed that when CAF was associated with $\mathrm{CM}$, the mean width recorded at the end of 6 months was $0.37 \mathrm{~mm}(\mathrm{SD}=1.18 \mathrm{~mm})$ greater than the observed with CAF. The discrepancy between the findings of this study and those reported in the literature after $\mathrm{CAF}+\mathrm{CM}$ could be explained by differences in the method of assessment. In the present study, MGJ identification was performed after staining with iodine solution (Lugol). There are indications that the functional method may result in greater KTW than the staining method [46]. Nevertheless, it is interesting to consider that KTW may not be a significant factor for the gingival margin stability in the long term $[47,48]$.

The healing pattern after root coverage procedures is characterized by a combination of new attachment in the apical portion and repair in the coronal part of the defect, through a long junctional epithelium and connective tissue adhesion [49-52]. Around 5 weeks after surgical procedure, the flap is reattached to the tooth and connective tissue appears to be completely regenerated [53-55]. When CM was sutured under the flap, a defined junctional epithelium and supra-crestal connective tissue with healthy fibrous structure were observed 1 month after surgery, in an animal model [56]. In human histology, a long junctional epithelial attachment as well as connective tissue adhesion has been shown 4 months after treatment with CAF + CM [35]. This healing pattern seems to be compatible with the changes in CAL associated with no significant changes in PD during all evaluation periods of the present study.

Dentin hypersensitivity is one of the important problems associated with gingival recession. The two tested treatments showed consistent reduction in DHS reported by patients at the end of study. Although inter-group difference was not significant, CAF + CTG yielded $80 \%$ DHS reduction compared with $62.5 \%$ DHS reduction in cases treated with CAF alone. One point to be considered as a limitation is the possibility of some placebo effect when evaluating DHS in both groups.

Another important aspect is the patient opinion about the esthetic result. Overall patient satisfaction was confirmed by consistent improvement in esthetic perception, with scores greater than 90 for both groups. However, patient esthetic satisfaction showed no differences between groups. The subjective nature of this type of investigation must be recognized, but since root coverage is indicated mainly to deal with a patient complain involving DHS/poor esthetics, it seems necessary to have some information about that after different surgical approaches.

The findings of the present short-term study do not support a superior outcome for the $\mathrm{CAF}+\mathrm{CM}$ group regarding recession reduction; however, some improvement on the soft tissue thickness may be expected after this approach. There is a need for more studies with longer follow-up periods to verify the influence of this collagen matrix on the stability of the gingival margin position.

\section{Conclusion}

Within the limits of the present study, it can be concluded that both approaches may provide effective short-term reduction in gingival recession. The combination of $\mathrm{CM}$ with $\mathrm{CAF}$ does not provide superior results in terms of recession reduction after 6 months; however, it slightly increases tissue thickness.

Acknowledgments The authors would like to thank Renato Corrêa Viana Casarin for their valuable comments with respect to the statistical analysis of this manuscript and Geistlich Pharma AG that provided the porcine collagen matrix tested in the present study.

Compliance with ethical standards This study was performed in accordance with ethical standards of the Institutional Review Board of the State University of Campinas (CEP-UNICAMP 130/2010).

Conflict of interest The authors declare that they have no competing interests.

Funding The work was supported by the Department of Prosthodontics and Periodontics, Division of Periodontics, Piracicaba Dental School, State University of Campinas-UNICAMP.

Informed consent Written informed consent was obtained of each subject included in the study. 


\section{References}

1. Wennström JL (1996) Mucogingival therapy. Ann Periodontol 1: 671-701

2. Serino G, Wennström JL, Lindhe J, Eneroth L (1994) The prevalence and distribution of gingival recession in subjects with a high standard of oral hygiene. J Clin Periodontol 21:57-63

3. Susin C, Haas AN, Oppermann RV, Haugejorden O, Albandar JM (2004) Gingival recession: epidemiology and risk indicators in a representative urban Brazilian population. J Periodontol 75:13771386

4. Toker H, Ozdemir H (2009) Gingival recession: epidemiology and risk indicators in a university dental hospital in Turkey. Int J Dent Hyg 7:115-120

5. Sarfati A, Bourgeois D, Katsahian S, Mora F, Bouchard P (2010) Risk assessment for buccal gingival recession defects in an adult population. J Periodontol 81:1419-1425

6. Nguyen-Hieu T, Ha-Thi B (2012) Gingival recession associated with predisposing factors in young vietnamese: a pilot study. Oral Health Dent Manag 11:134-144

7. Sangnes G, Gjermo P (1976) Prevalence of oral soft and hard tissue lesions related to mechanical toothcleansing procedures. Community Dent Oral Epidemiol 4:77-83

8. Litonjua LA, Andreana S, Bush PJ, Cohen RE (2003) Toothbrushing and gingival recession. Int Dent J 53:67-72

9. Rajapakse PS, McCracken GI, Gwynnett E, Steen ND, Guentsch A, Heasman PA (2007) Does tooth brushing influence the development and progression of non-inflammatory gingival recession? A systematic review. J Clin Periodontol 34:1046-1061

10. Allen EP, Miller PD (1989) Coronal positioning of existing gingiva: short term results in the treatment of shallow marginal tissue recession. J Periodontol 60:316-319

11. Tonetti MS, Jepsen S (2014) Clinical efficacy of periodontal plastic surgery procedures: consensus report of Group 2 of the 10th European Workshop on Periodontology. J Clin Periodontol 41(Suppl 1):S36-S43

12. Miller PD (1985) A classification of marginal tissue recession. Int J Periodontics Restorative Dent 5:8-13

13. Wennström JL (1996) Mucogingival considerations in orthodontic treatment. Semin Orthod 2:46-54

14. Chambrone L, Chambrone D, Pustiglioni FE, Chambrone LA, Lima LA (2008) Can subepithelial connective tissue grafts be considered the gold standard procedure in the treatment of Miller Class I and II recession-type defects? J Dent 36:659-671

15. Langer B, Langer L (1985) Subepithelial connective tissue graft technique for root coverage. J Periodontol 56:715-720

16. Côrtes Ade Q, Martins AG, Nociti FH, Sallum AW, Casati MZ, Sallum EA (2004) Coronally positioned flap with or without acellular dermal matrix graft in the treatment of Class I gingival recessions: a randomized controlled clinical study. J Periodontol 75: 1137-1144

17. Prato GP, Tinti C, Cortellini P, Magnani C, Clauser C (1992) Periodontal regenerative therapy with coverage of previously restored root surfaces: case reports. Int J Periodontics Restorative Dent 12:450-461

18. Modica F, Del Pizzo M, Roccuzzo M, Romagnoli R (2000) Coronally advanced flap for the treatment of buccal gingival recessions with and without enamel matrix derivative. A Split-mouth Study J Periodontol 71:1693-1698

19. Cairo F, Nieri M, Pagliaro U (2014) Efficacy of periodontal plastic surgery procedures in the treatment of localized facial gingival recessions. A Syst Rev J Clin Periodontol 41(Suppl 1):S44-S62

20. Roccuzzo M, Bunino M, Needleman I, Sanz M (2002) Periodontal plastic surgery for treatment of localized gingival recessions: a systematic review. J Clin Periodontol 29(Suppl 3):178-194 discussion 195-6

21. Clauser C, Nieri M, Franceschi D, Pagliaro U, Pini-Prato G (2003) Evidence-based mucogingival therapy. Part 2: ordinary and individual patient data meta-analyses of surgical treatment of recession using complete root coverage as the outcome variable. J Periodontol 74:741-756

22. Chambrone L, Sukekava F, Araújo MG, Pustiglioni FE, Chambrone LA, Lima LA (2010) Root-coverage procedures for the treatment of localized recession-type defects: a Cochrane systematic review. J Periodontol 81:452-478

23. Cortellini P, Tonetti M, Baldi C, Francetti L, Rasperini G, Rotundo $R$, et al. (2009) Does placement of a connective tissue graft improve the outcomes of coronally advanced flap for coverage of single gingival recessions in upper anterior teeth? A multi-centre, randomized, double-blind, clinical trial. J Clin Periodontol 36:68-79

24. Romagna-Genon C (2001) Comparative clinical study of guided tissue regeneration with a bioabsorbable bilayer collagen membrane and subepithelial connective tissue graft. J Periodontol 72:12581264

25. Zucchelli G, Amore C, Sforza NM, Montebugnoli L, De Sanctis M (2003) Bilaminar techniques for the treatment of recession-type defects. A comparative clinical study. J Clin Periodontol 30:862870

26. Keceli HG, Sengun D, Berberoğlu A, Karabulut E (2008) Use of platelet gel with connective tissue grafts for root coverage: a randomized-controlled trial. J Clin Periodontol 35:255-262

27. De Queiroz CA, Sallum AW, Casati MZ, Nociti FH, Sallum EA (2006) A two-year prospective study of coronally positioned flap with or without acellular dermal matrix graft. J Clin Periodontol 33: 683-689

28. Alves LB, Costa PP, Scombatti de Souza SL, de Moraes Grisi MF, Palioto DB, Taba M Jr, et al. (2012) Acellular dermal matrix graft with or without enamel matrix derivative for root coverage in smokers: a randomized clinical study. J Clin Periodontol 39:393399

29. McGuire MK, Scheyer ET (2010) Xenogeneic collagen matrix with coronally advanced flap compared to connective tissue with coronally advanced flap for the treatment of dehiscence-type recession defects. J Periodontol 81:1108-1117

30. Cardaropoli D, Tamagnone L, Roffredo A, Gaveglio L (2012) Treatment of gingival recession defects using coronally advanced flap with a porcine collagen matrix compared to coronally advanced flap with connective tissue graft: a randomized controlled clinical trial. J Periodontol 83:321-328

31. Aroca S, Molnár B, Windisch P, Gera I, Salvi GE, Nikolidakis D, et al. (2013) Treatment of multiple adjacent Miller class I and II gingival recessions with a Modified Coronally Advanced Tunnel (MCAT) technique and a collagen matrix or palatal connective tissue graft: a randomized, controlled clinical trial. J Clin Periodontol 40:713-720

32. Jepsen K, Jepsen S, Zucchelli G, Stefanini M, de Sanctis M, Baldini $\mathrm{N}$, et al. (2013) Treatment of gingival recession defects with a coronally advanced flap and a xenogeneic collagen matrix: a multicenter randomized clinical trial. J Clin Periodontol 40:82-89

33. Molnár B, Aroca DMDS, Keglevich T, Gera I, Windisch P, Sculean A, et al. (2013) Treatment of multiple adjacent Miller Class I and II gingival recessions with collagen matrix and the modified coronally advanced tunnel technique 44:17-25

34. Ghanaati S, Schlee M, Webber MJ, Willershausen I, Barbeck M, Balic E, et al. (2011) Evaluation of the tissue reaction to a new bilayered collagen matrix in vivo and its translation to the clinic. Biomed Mater 6:015010

35. Camelo M, Nevins M, Nevins ML, Schupbach P, Kim DM (2012) Treatment of gingival recession defects with xenogenic collagen 
matrix: a histologic report. Int J Periodontics Restor Dent 32:167173

36. Pini-Prato G, Franceschi D, Cairo F, Nieri M, Rotundo R (2010) Classification of dental surface defects in areas of gingival recession. J Periodontol 81:885-890

37. Ainamo J, Bay I (1975) Problems and proposals for recording gingivitis and plaque. Int Dent J 25:229-235

38. Mühlemann H, Son S (1971) Gingival sulcus bleeding - a leading symptom in initial gingivitis. Helv Odontol Acta 15:107-113

39. Cairo F, Rotundo R, Miller PD, Pini Prato GP (2009) Root coverage esthetic score: a system to evaluate the esthetic outcome of the treatment of gingival recession through evaluation of clinical cases. J Periodontol 80:705-710

40. Kerner S, Sarfati A, Katsahian S, Jaumet V, Micheau C, Mora F, et al. (2009) Qualitative cosmetic evaluation after root-coverage procedures. J Periodontol 80:41-47

41. Pagliaro U, Nieri M, Franceschi D, Clauser C, Pini-Prato G (2003) Evidence-based mucogingival therapy. Part 1: a critical review of the literature on root coverage procedures. J Periodontol 74:709740

42. Da Silva RC, Joly JC, de Lima AFM, Tatakis DN (2004) Root coverage using the coronally positioned flap with or without a subepithelial connective tissue graft. J Periodontol 75:413-419

43. Zucchelli G, Mele M, Stefanini M, Mazzotti C, Marzadori M, Montebugnoli L, et al. (2010) Patient morbidity and root coverage outcome after subepithelial connective tissue and de-epithelialized grafts: a comparative randomized-controlled clinical trial. J Clin Periodontol 37:728-738

44. Ahmedbeyli C, Ipçi ȘD, Cakar G, Kuru BE, Yılmaz S (2014) Clinical evaluation of coronally advanced flap with or without acellular dermal matrix graft on complete defect coverage for the treatment of multiple gingival recessions with thin tissue biotype. J Clin Periodontol 41:303-310

45. Müller HP, Eger T (1997) Gingival phenotypes in young male adults. J Clin Periodontol 24:65-71
46. Bernimoulin JP, Son S, Regolati B (1971) Biometric comparison of three methods for determining the mucogingival junction. Helv Odontol Acta 15:118-120

47. Tenenbaum H (1982) A clinical study comparing the width of attached gingiva and the prevalence of gingival recessions. J Clin Periodontol 9:86-92

48. Wennström JL (1987) Lack of association between width of attached gingiva and development of soft tissue recession. A 5-year longitudinal study. J Clin Periodontol 14:181-184

49. Pasquinelli KL (1995) The histology of new attachment utilizing a thick autogenous soft tissue graft in an area of deep recession: a case report. Int J Periodontics Restor Dent 15:248-257

50. Goldstein M, Boyan BD, Cochran DL, Schwartz Z (2001) Human histology of new attachment after root coverage using subepithelial connective tissue graft. J Clin Periodontol 28:657-662

51. Cummings LC, Kaldahl WB, Allen EP (2005) Histologic evaluation of autogenous connective tissue and acellular dermal matrix grafts in humans. J Periodontol 76:178-186

52. McGuire MK, Scheyer ET, Schupbach P (2009) Growth factormediated treatment of recession defects: a randomized controlled trial and histologic and microcomputed tomography examination. J Periodontol 80:550-564

53. Caffesse RG, Kon S, Castelli WA, Nasjleti CE (1984) Revascularization following the lateral sliding flap procedure. J Periodontol 55:352-358

54. Kon S, Caffesse RG, Castelli WA, Nasjleti CE (1984) Revascularization following a combined gingival flap-split thickness flap procedure in monkeys. J Periodontol 55:345-351

55. Sculean A, Gruber R, Bosshardt DD (2014) Soft tissue wound healing around teeth and dental implants. J Clin Periodontol 41(Suppl 1):S6-22

56. Vignoletti F, Nuñez J, Discepoli N, De Sanctis F, Caffesse R, Muñoz F, et al. (2011) Clinical and histological healing of a new collagen matrix in combination with the coronally advanced flap for the treatment of Miller class-I recession defects: an experimental study in the minipig. J Clin Periodontol 38:847-855 